\title{
Interfacial characterisation of overcasting a cast Al-Si-Mg (A356) alloy on a wrought Al-Mg-Si (AA6060) alloy
}

Yijie Zhang, Shouxun Ji*, Geoff Scamans, Zhongyun Fan

Brunel Centre for Advanced Solidification technology (BCAST), Institute of Materials, Brunel University London, Uxbridge, Middlesex UB8 3PH, United Kingdom

*Corresponding author. Tel.: +441895266663; Fax: +441895269758; E-mail address: shouxun.ji@brunel.ac.uk.

\begin{abstract}
The microstructure and tensile properties of hybrid Al-Si-Mg (A356) and Al-Mg-Si (AA6060) materials were investigated through overcasting. The solid bonding at AA6060/A356 interface was obtained under as-cast condition and T7 heat-treated condition. The oxide film on the surface of the AA6060 inserts was successfully removed by properly designed casting structure and optimised overcasting process. Fine equiaxed primary $\alpha$-Al grains could be formed at the bonding interface, during which the primary $\alpha$-Al grains in the A356 alloy were grown up on the primary $\alpha$-Al grains in the solid inserts of AA6060 alloy. EBSD results revealed that these two types of primary $\alpha$-Al grains exhibited the same orientation, indicating the cast A356 alloy and the wrought AA6060 alloy shared one primary $\alpha$-Al grain at the interface. The interfacial bonding strength was measured at a level of $180 \mathrm{MPa}$. Heat-affected zone was not significant in the overcast structure because the decrease of the ultimate tensile strength of overcast arts was only 3-5\% in comparison with the properties of the original AA6060 alloys under aged condition.
\end{abstract}

Keywords: Aluminium alloys; Bonding; Microstructure; Mechanical properties; Overcasting; Interfaces 


\section{Introduction}

Light metal overcasting is one of the recently developed methods to join hybrid structures that have great relevance for technical applications. The process of joining solid metal and liquid metal together also was defined as compound casting. Papis et al. (2008) developed the compound casting to join a wrought alloy part with cast components by casting a light metal onto or around the solid component. Koerner et al. (2014) applied the compound casting to form $\mathrm{AlSi}_{9} \mathrm{Cu}_{3}(\mathrm{Fe})$ component with solid $\mathrm{Al}$ insert via high pressure die casting, and confirmed that a firmly bonded interface could be obtained without embrittlement intermetallic phases. In view of the thermodynamically stable natural aluminium oxide layer on solid $\mathrm{Al}$ inserts, good bonding interfaces are critical to understand the joining mechanisms and benefit the process improvement. Therefore, the interface between an aluminium melt and solid inserts has been the topics of a number of researches. The experiment results of Jiang et al. (2015) indicated that the surface modifier method of aluminizing can promote a sound surface and metallurgical bonding between steel/Al prepared by a compound casting process. Dezellus et al. (2007) studied the formation of interface layer by immersing mild steel into Al-Si alloy melts and the mechanical properties of interface by pushout test. The results showed that the $\mathrm{Al}_{5} \mathrm{Fe}_{2} \mathrm{Si}$ and $\mathrm{Al}_{9} \mathrm{Fe}_{2} \mathrm{Si}_{2}$ phases would form during immersing and the crack initiation would occur in the intermetallic reaction layer.

The interface between steel/iron inserts and aluminium melt has been obtained by immersing the steel/iron into aluminium melt or overcasting aluminium melt onto the steel/iron inserts, which was triggered by the durability study of manufacturing tools. It was reported by Uthayakumar et al. (2009) that the application of a cast iron insert reinforced Al piston was generaly employed in diesel engines of heavy duty vehicles to meet weight savings and production cost requirements. Viala et al. (2002) prepared an iron base insert reinforced Al-Si suspension part by gravity die casting and revealed that a continuous metallurgical bond at the iron insert/Al-Si alloy interface can be achieved. An Al-Fin bond in Al piston alloy and austenitic cast iron insert studied by Manasijevic et al. (2015) showed that a good metallic bond could be obtained between the two materials via the formation of $\mathrm{FeAl}_{3}$ and $\mathrm{Fe}_{2} \mathrm{Al}_{5}$ intermetallic phases on the interface. Lombardi et al. (2015) investigated the development of 
residual strain of $\mathrm{Al}$ engine blocks with gray iron cylinder liners during post treatment cooling, in which engine blocks were fabricated by precision sand casting with Cosworth process. Bouayad et al. (2003) revealed that several intermetallic compounds including $\gamma-\mathrm{Al}_{3} \mathrm{FeSi}$, and $\eta-\mathrm{Al}_{5} \mathrm{Fe}_{2}(\mathrm{Si})$ and $\beta-\mathrm{Al}_{5} \mathrm{FeSi}$ could be formed at the interface, which were the reaction products at different times and different temperatures. The common reaction layer sequence reported by Kobayashi and Yakou (2002) was $\mathrm{Fe} / \mathrm{Fe}_{2} \mathrm{Al}_{5} / \mathrm{FeAl}_{3} / \mathrm{Al}$. The investigation of Zhang et al. (2013) showed that the sequence of reaction layer was $\mathrm{Fe} / \eta-\mathrm{Al}_{5} \mathrm{Fe}_{2}(\mathrm{Si}) / \beta-\mathrm{Al}_{5} \mathrm{FeSi} / \mathrm{Al}-\mathrm{Si}$. It has also been found by Arghavani et al. (2016) that a $\mathrm{Zn}$ coating on steel surface could enhance the wettability of bonding surface between steel and A5052 Al alloy. Liu et al. (2014) found that the kinds of intermetallic compound of $\mathrm{Al}_{5} \mathrm{Fe}_{2} \mathrm{Zn}_{\mathrm{x}}$ and $\mathrm{Al}_{3} \mathrm{FeZn}_{\mathrm{x}}$ was formed on the interface between hot-dip galvanized steel and pure Al after compound casting. The work done by Shao et al. (2015) indicated that Zn coating would evaporate during joining the $\mathrm{Al}$ and galvanized steel together by pulsed double electrode gas metal arc welding.

Recently, the study of overcasting between cast aluminium and wrought aluminium becomes more interesting for lightweight structure. Because the natural oxide layer on the surface of aluminium alloys is condensate, thermodynamically stable and can be formed very quickly after being removed or scratched even within trace-oxygen atmosphere, it has to be eliminated during the overcasting process in order to obtain a good joining. Currently, the main efforts are focused on zincate. Papis et al. (2008) found that the Zn-coating on aluminium yielded wetting angles between solid and liquid aluminium alloys of $10^{\circ}$ and less, allowing the formation of interface free from imperfections and a continuous metallurgical bond. Rübner et al. (2011) tried overcasting AlSi9Cu3(Fe) on Zn-coated Al99.5 and found a transit Al-Zn-Si layer between the cast and wrought alloys. Liu et al. (2015) tried to overcast A356 on A6101 and found that the transition zone was formed when Zn-coating was more than $5 \mu \mathrm{m}$ thick and that the fracture was occurred in the transition zone. Nerl et al. (2014) found the maximum temperature at the interface was a decisive parameter to obtain proper metallurgical compounds between the AlSn6Cu alloy and pure aluminium. Generally, the Zn-rich layer may still exist in the final microstructure and becomes the weak locations under 
stress because of the characteristics of pure Zn. Therefore, the Zn-rich layer may be detrimental to the mechanical properties. This had been partially confirmed by Schwankl et al. (2016) that the interface strength determined by zinc was the weakest part of the wrought $\mathrm{Al}$-cast $\mathrm{Al}$ compound castings. Ideally, the bonding interface between the cast alloy and the wrought alloy should be integrated with smooth solute distribution. Therefore, the microstructure and mechanical properties of the hybrid materials obtained by overcasting aluminium melt on the inserts without any coating and specific treatment are attractive for improving the bonding strength and process applications.

In the present work, the overcasting of a cast A356 alloy on the extruded AA6060 plates without any surface treatment was studied using a specific mould to obtain required interface in the hybrid materials. The solidification, microstructural evolution and mechanical properties were characterised by different techniques. The discussion is focused on the understanding of bonding mechanism at the interface, and the relationship between microstructural characterisation and mechanical properties.

\section{Experimental}

The experiments were carried out in a specially designed casting structure, as shown in Fig. 1. The hybrid structure (Fig. 1a) consisted of two AA6060 plates and one A356 overcasting in the middle to join the plates together with a given depth surrounding the plates, and a gating system to one side and an overflow/riser on the opposite of the plates, as shown in Fig. 1. The AA6060 plate was $50 \mathrm{~mm}$ long, $20 \mathrm{~mm}$ wide and $2 \mathrm{~mm}$ thick (Fig. 1a). The AA6060 alloy was extruded in an industrial scale with online quenching system to obtain the profile under T4 condition for overcasting investigation. The geometry of the overcasting was $40 \mathrm{~mm}$ long, $23 \mathrm{~mm}$ wide and $5 \mathrm{~mm}$ thick. 

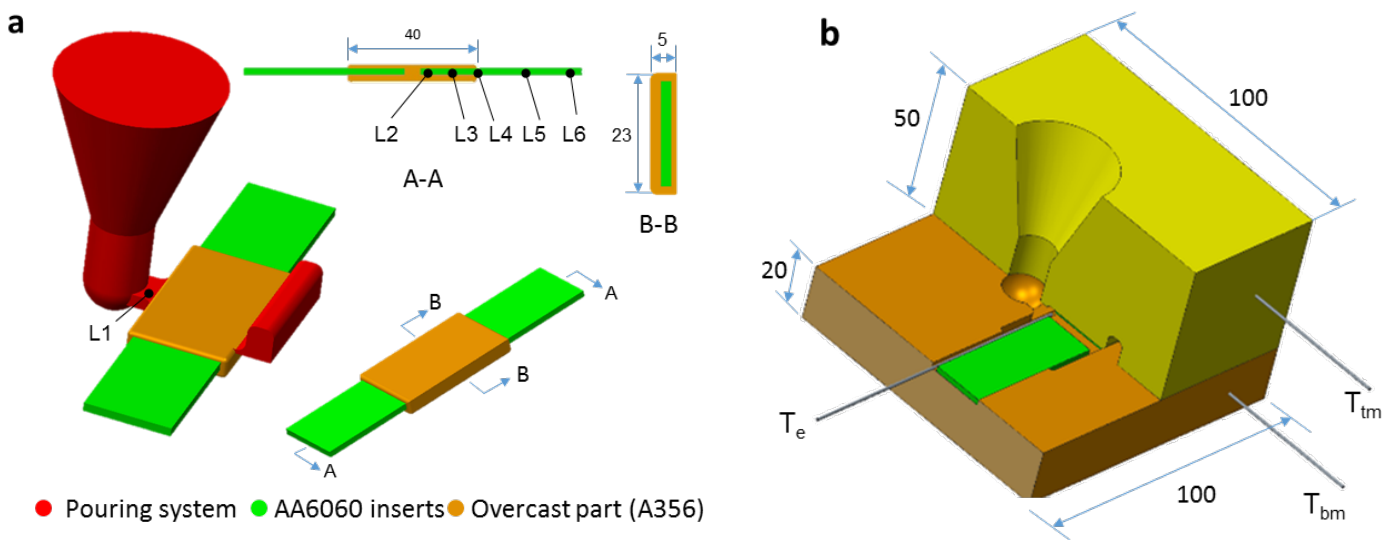

Figure 1 Schematic diagram of (a) overcasting structure with dimensions, (b) mould configuration for gravity overcasting $\left(\mathrm{T}_{\mathrm{e}}\right.$ : the melt temperature at cavity entrance, $\mathrm{T}_{\mathrm{tm}}$ : the temperature of top mould, $\mathrm{T}_{\mathrm{bm}}$ : the temperature of bottom mould, L1, L2, L3, L4, L5 and L6: locations for data acquisition from the calculated solidification and cooling process, and for measuring the temperature distribution).

The hybrid structure was made by a metallic mould (Fig. 1b). During experiments, the AA6060 plates were preheated to different temperatures, and pre-set in the mould with different gap distances. The casting parameters were selected by simulation results obtained by ProCAST. The compositions of the two alloys used in experiments are given in Table 1.

Table 1. The chemical compositions of AA6060 and A356 alloys used in the experiments.

\begin{tabular}{ccccccccc}
\hline & \multicolumn{7}{c}{ Compositions (wt.\%) } \\
Material & $\mathrm{Si}$ & $\mathrm{Mg}$ & $\mathrm{Mn}$ & $\mathrm{Ti}$ & $\mathrm{Fe}$ & $\mathrm{Cr}$ & $\mathrm{Zn}$ & $\mathrm{Al}$ \\
\hline AA6060 & 0.46 & 0.45 & 0.03 & 0.02 & 0.20 & 0.04 & 0.003 & Bal. \\
A356 & 6.8 & 0.32 & $/$ & 0.01 & 0.12 & $/$ & $/$ & Bal. \\
\hline
\end{tabular}

During casting, the A356 alloy was melted at $750^{\circ} \mathrm{C}$ in a furnace using a graphite-clay crucible. After one hour of homogenisation, the melt was subjected to degassing, during which argon was introduced into the melt by a commercial rotatory degasser at 500 rpm for 3 min and the top surface of the melt was covered by commercial granular flux. The melt was subsequently homogenised in the furnace for $30 \mathrm{~min}$. After skimming, the melt was manually 
poured into the mould for overcasting.

The as-cast samples were heat treated in an electric resistance furnace that was preheated to a given temperature and maintained the temperature consistently for at least one hour before putting the overcast samples into the furnace chamber. The temperature inside the chamber was monitored by a separate thermocouple with an accuracy of $\pm 0.5^{\circ} \mathrm{C}$ during the heat treatment. The samples were water quenched immediately after solutionising treatment, but just taken out from the furnace for air cooling after ageing treatment. The casting samples were then machined to standard tensile samples, as shown in Fig. 2.

a

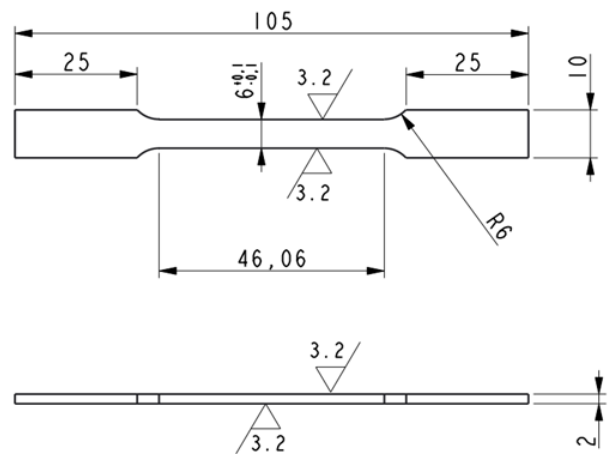

b

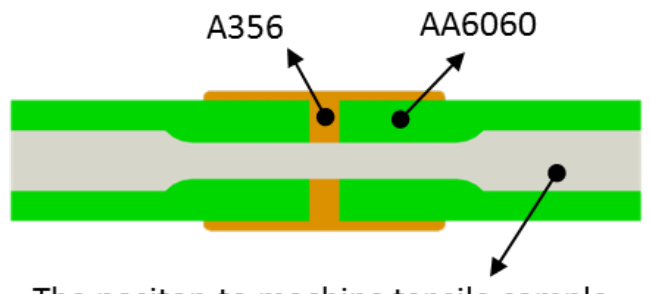

The positon to machine tensile sample

Figure 2 (a) The tensile sample size and (b) the location of tensile sample machined from the hybrid materials made by overcasting the A356 on the AA6060 solid inserts.

The tensile tests were conducted following ASTM standard B557-15, using an Instron 5500 Universal Electromechanical Testing System equipped with Bluehill controls software and a $\pm 50 \mathrm{kN}$ load cell. All tensile tests were performed at an ambient temperature $\left(\sim 20^{\circ} \mathrm{C}\right)$. The gauge length of the extensometer was $25 \mathrm{~mm}$ and the ramp rate for extension was $1 \mathrm{~mm} / \mathrm{min}$. Each set of data reported was based on the properties obtained from 3 to 5 samples. Hardness test was conducted using a Wilson 432SVA digital auto turret macro Vickers Hardness Tester. All hardness test samples were prepared by a standard technique. The hardness tester was calibrated using a standard sample. A $0.1 \mathrm{~kg}$ loading force and $10 \mathrm{~s}$ test time were selected throughout the experiments. The reported data of hardness was taken from the average of 5 to 8 points measured in each sample. 
Samples for metallographic examination were prepared by a standard technique. Anodization of samples into $4 \% \mathrm{HBF}_{4}$ water solution for 1 minute at $20 \mathrm{~V}$ was employed to observe the grain size of materials via Zeiss optical microscopy, which is equipped with an Axio Vision4.3 Quantimet digital image analysis system for quantitative metallography. Field-emission scanning electron microscopy (FE-SEM, SUPRA 35VP, Carl-Zeiss Company) equipped with an energy dispersive X-ray spectroscopy (EDS) was also used for microstructure analysis, during which five different fields of view were analysed for each specimen and the average was taken as the measured value. The quantitative SEM/EDS analysis was performed at an accelerating voltage of $20 \mathrm{kV}$ with calibration being carried out before each session. The microstructure was also characterised by EBSD orientation mapping in the Zeiss Supera 35 FEGSEM equipped with an Oxford Instrument EBSD system.

\section{Results}

\subsection{Cooling during overcasting}

In order to figure out the solidification in the overcasting at different locations and the temperature distribution in the inserts during the overcasting process, the temperature variations were calculated using the commercial software package of ProCAST, during which a standard procure was followed for meshing inserts and castings and setting boundary conditions. The database integrated with software package were used to select physical properties of A6060 and A356 alloys The temperature profiles at different locations marked in Fig. 1 were extracted and shown in Fig. 3. It is clear that the cooling curves were different, but the final temperatures a couple of minutes later at different locations were very close in the overcast structure. The results also confirmed that the temperatures at the location away from the melt entrance were lower, which correspond to the heat transfer during solidification. The peak temperatures at different locations are summarised in the insert in Fig.3. The location L1 was the entrance point for the melt into the cast cavity. It is seen that the temperature at L1 was higher, but the temperatures at other locations were lower than the liquidus of the A356 alloy. Generally, the criteria of parameter selection is that the melt must be in liquid state during entering and flowing through the casting cavity to maintain required 
filling behaviour, but the melt should not have a large overheat to form fine grain structure. According to this criteria and the calculation results, the pouring temperature, mould temperature and AA6060 preheat temperature were preferably selected at $720 \pm 5^{\circ} \mathrm{C}$, $450 \pm 10^{\circ} \mathrm{C}$, and $200 \pm 10^{\circ} \mathrm{C}$ respectively.

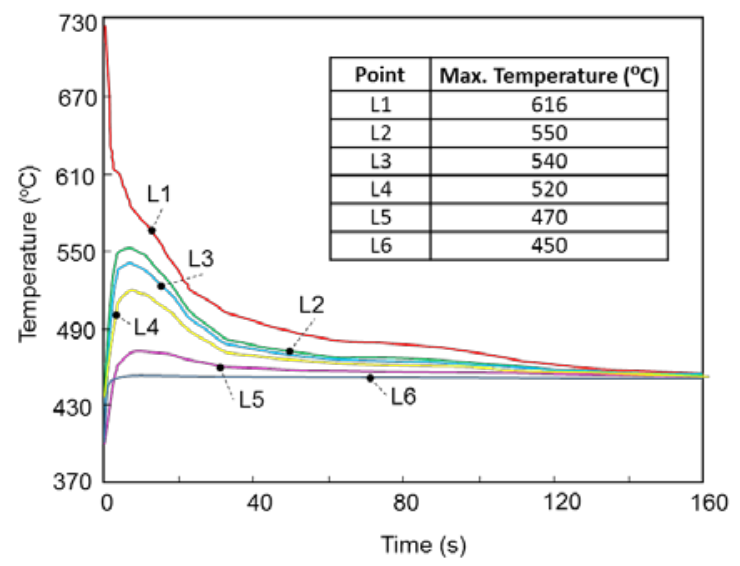

Figure 3 the cooling curves at different locations specified in Fig.1(a), in which point L1 is the entrance point of the melt into the casting cavity.

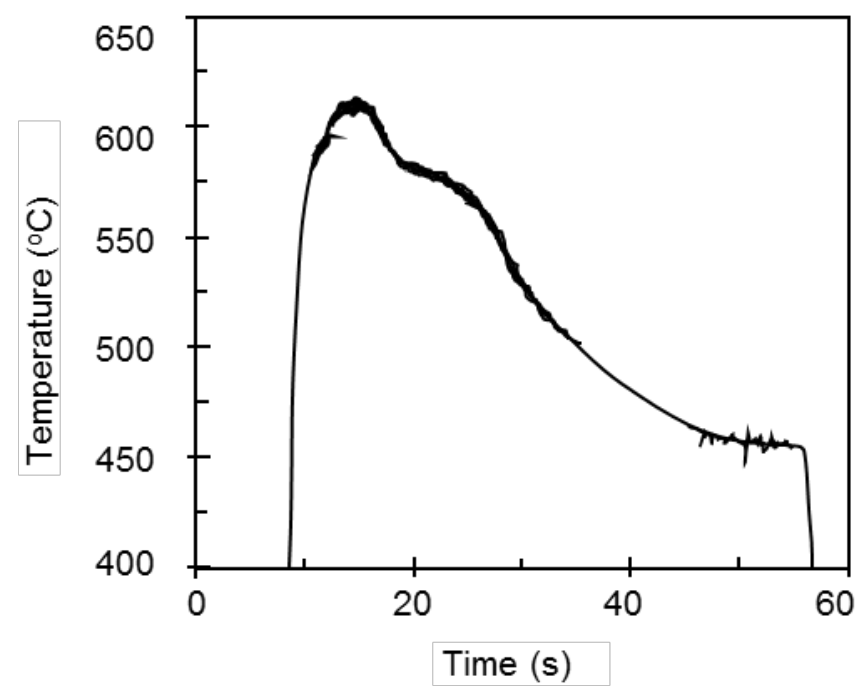

Figure 4 Measured cooling curve at the cavity entrance point of the overcasting A356 alloy melt (the location L1 marked in Fig. 1 )

To verify the temperature and cooling curves in the overcasting, three thermocouples were pre-set to measure the temperatures at different locations (as shown in Fig. 1b). Fig. 4 shows the measured temperature variation at the entrance of overcasting cavity ( $T_{e}$ at $L 1$ ) when the 
AA6060 inserts were preheated to $200 \pm 10^{\circ} \mathrm{C}$. It is found that the A356 was introduced into the casting cavity in liquid state (the liquidus of A356 is $615^{\circ} \mathrm{C}$ ). More importantly, it is confirmed that the measured temperatures were in very good agreement with the results collected from the simulated temperatures (Fig. 3). In the meantime, it is also found that the temperatures of the AA6060 inserts in Fig. 3 were between 450 and $550^{\circ} \mathrm{C}$ during overcasting. Therefore, it is clear that the inserts were in solid state and not be able to be melted during overcasting because the solidus of AA6060 is $582^{\circ} \mathrm{C}$ and the liquidus is $652^{\circ} \mathrm{C}$.

\subsection{Microstructure in overcast structure}

Fig. 5 shows the microstructure of the region across the AA6060/A356 interface. The microstructure was featured with two zones around the interface. The first zone was in the wrought AA6060 adjacent to the interface, the band width was $50 \mu \mathrm{m}$, in which the primary $\alpha$-Al grains became precipitate free. The grain sizes in the precipitate-free zone are as the same as that in the AA6060 alloy. Due to the AA6060 inserts used in the present study was T7 (solutionised during extrusion and aged at $203{ }^{\circ} \mathrm{C}$ for 11 hours) heat-treated before being used for overcasting and there should be $1.4 \mathrm{wt} . \% \mathrm{Mg}_{2} \mathrm{Si}$ and $0.21 \mathrm{wt} . \%$ free Si. The clean band in the microstructure at the interface indicated that there were no obvious precipitates within the grains during the heating cycles from overcasting.

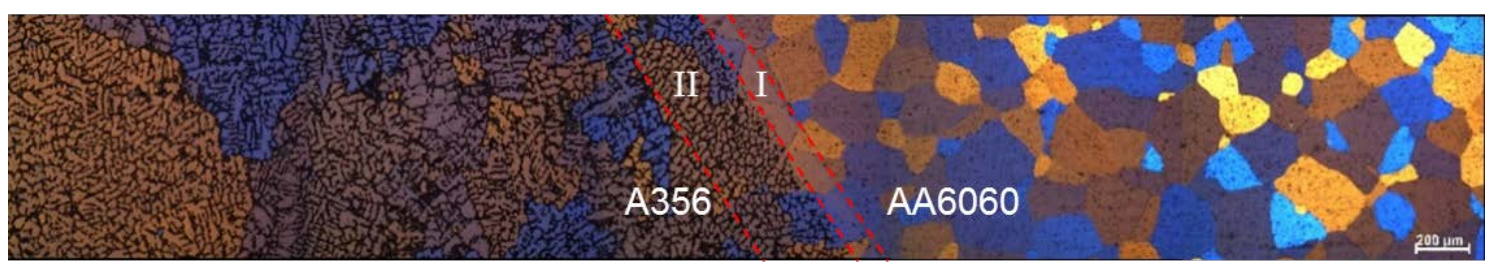

Figure 5 The optical micrograph showing the interface between the AA6060 insert and the overcast A356 alloy.

The second zone was in the cast A356 alloy adjacent to the interface. The width of the zone II was about $200 \mu \mathrm{m}$. The as-cast microstructure was featured by fine equiaxed $\alpha$-Al grains, in which the size of secondary dendrite arm spacing (SDAS) was measured as $23.5 \mu \mathrm{m}$. Moreover, the reactions were observed at the AA6060/A356 interface. As shown in Fig. 6, the as-cast microstructure shared $\alpha$-Al grains between the cast A356 and the wrought AA6060 
at the interface. It means that the nucleation and growth of $\alpha$-Al grains in the A356 were based on the existing $\alpha$-Al grains in the AA6060 inserts. In order to confirm whether the grain at the interface was grown from the existing AA6060 alloy, EBSD analysis was undertaken and the results are shown in Fig. 7. The image showed that the $\alpha$-Al grain in the A356 and the $\alpha$-Al grain in the AA6060 had the same orientation. This is the evidence indicating that the $\alpha$-Al grain in the A356 must have nucleated on the existing $\alpha$-Al grain in the AA6060 substrate and subsequently grown along the grain orientation of the AA6060 from the interface.

To reveal the hardness on interface, the point analysis cross the interface was conducted and the results are also shown in Fig.6. According to the composition analysis across the A6060/A356 interface, there was a difference of the Si content on the interface of A6060 matrix and A356 matrix. The Si content in the precipitate-free zone was higher than that of A6060 and lower than that of A356. This means that the diffusion of Si into the A6060 matrix was occurred during overcasting. The dissolved Si into matrix could form solution hardening and resulted in the increase of hardness in the matrix.

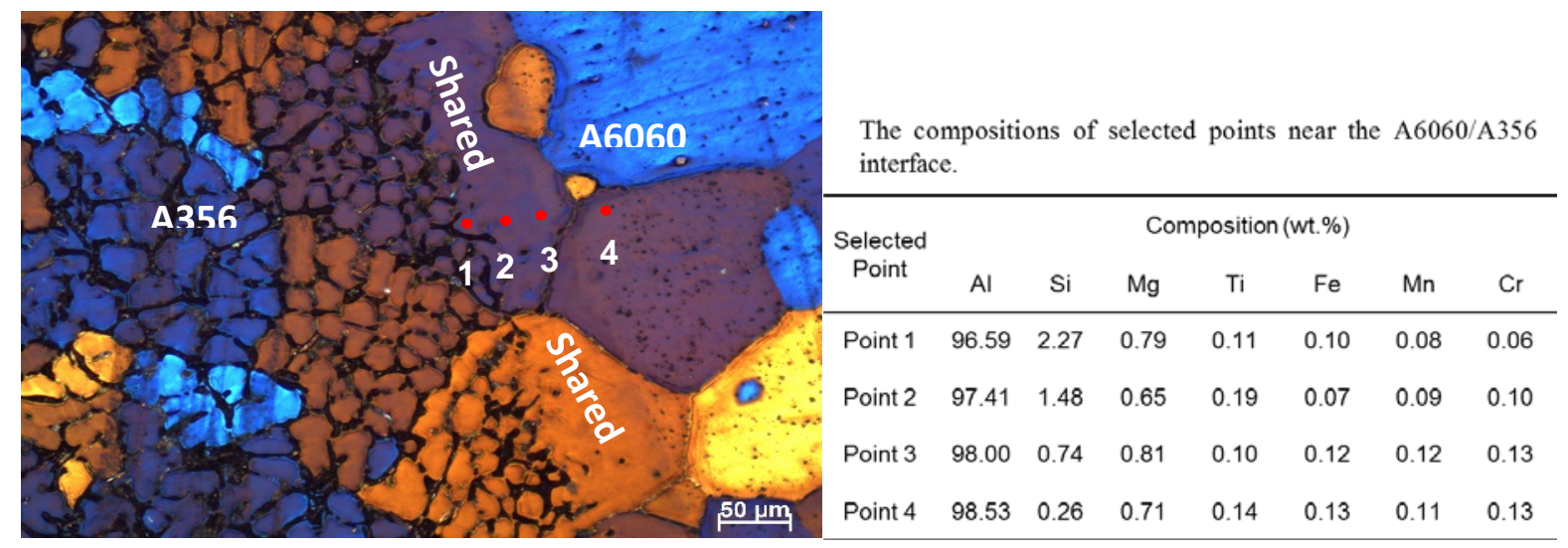

Figure 6 The optical micrograph showing the shared $\alpha$-Al grains at the interface between the A6060 insert and the overcast A356 alloy. And insert table was the composition analysis of selected points crossing the A6060/A356 interface. 


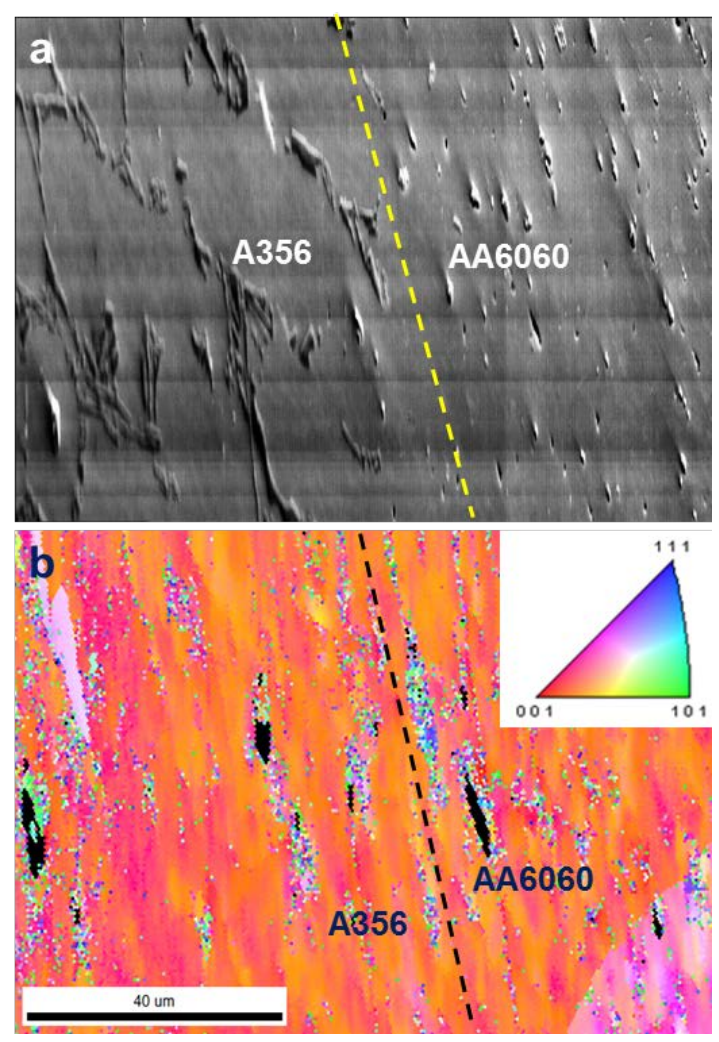

Figure 7 (a) SEM image showing the location and microstructural features for EBSD analysis, (b) EBSD image showing the distribution of grain orientation and the color coded map of inverse pole [001] at the interface between the AA6060 insert and the overcast A356 alloy.

\subsection{Mechanical properties in overcast structure}

The hybrid structural parts were machined across the interface to make samples with the sizes shown in Fig. 2 for tensile test, which comply with the standard specification defined in ASTM B557-15. The samples were subsequently tested to evaluate the bonding strength across the AA6060/A356 interface. Fig. 8 shows the fractured samples (marked by triangles for the fracture locations) under as-cast and under aged conditions, respectively. It is seen that the fracture of overcasting arts did not occur along the AA6060/A356 interface, but occurred within the cast A356 under as-cast condition and within the wrought AA6060 after being aged at $203^{\circ} \mathrm{C}$ for 11 hours. The results confirmed that the cast A356 was weaker than the wrought AA6060 inserts under as-cast condition, but vice versa after being aged. It also indicated that the bonding strength in the interface was stronger than the strength within the original alloys. 


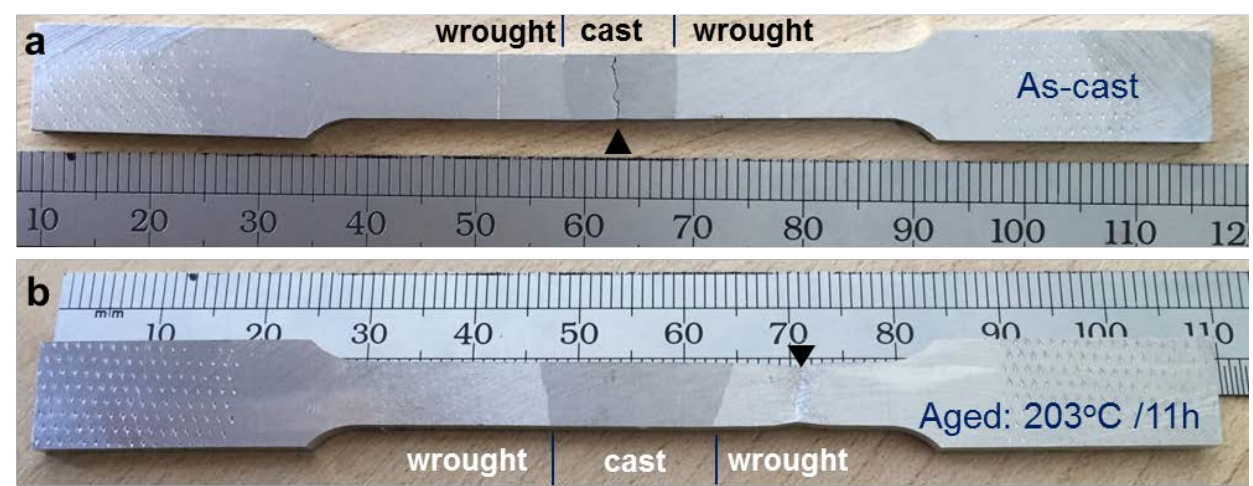

Figure 8 Optical images showing the positions of fracture of the overcast AA6060/A356 tensile samples, (a) as-cast, (b) aged at $203^{\circ} \mathrm{C}$ for 11 hours (AA6060 was in T4 condition before being used for overcasting, therefore, the aged sample of the AA6060 alloy was under T7 condition after ageing).

Table 2 The mechanical properties of overcast tensile samples and the A356 and AA6060 used in the experiments.

\begin{tabular}{lcccc}
\hline Materials & Sample conditions & $\mathrm{Rp0} .2(\mathrm{MPa})$ & $\mathrm{Rm}(\mathrm{MPa})$ & $\delta(\%)$ \\
\hline $\begin{array}{l}\text { Overcast } \\
\text { sample }\end{array}$ & As-cast & $91 \pm 5.5$ & $178 \pm 12.6$ & $4 \pm 1.8$ \\
& Aged at $203^{\circ} \mathrm{C}$ for $11 \mathrm{~h}$ & $154 \pm 7.3$ & $180 \pm 10.6$ & $10 \pm 2.3$ \\
\multirow{2}{*}{ A356 } & As-cast & $80 \pm 6.6$ & $160 \pm 15.5$ & $4 \pm 1.5$ \\
& Aged at $203^{\circ} \mathrm{C}$ for $11 \mathrm{~h}$ & $165 \pm 7.1$ & $220 \pm 16.2$ & $4.5 \pm 2.2$ \\
\multirow{2}{*}{ AA6060 } & $\mathrm{T} 4$ (solutionised at $540^{\circ} \mathrm{C}$ for $\left.4 \mathrm{~h}\right)$ & $68 \pm 5.7$ & $131 \pm 9.7$ & $16 \pm 3.6$ \\
& $\mathrm{~T} 7$ (aged at $203^{\circ} \mathrm{C}$ for $\left.11 \mathrm{~h}\right)$ & $160 \pm 7.4$ & $190 \pm 12.3$ & $10 \pm 3.8$ \\
\hline
\end{tabular}

The tensile properties of overcast samples are summarised in Table 2 for different materials under different heat treatment conditions. The overcastings showed the yield strength (YS) of $91 \pm 5.5 \mathrm{MPa}$, ultimate tensile strength (UTS) of $178 \pm 12.6 \mathrm{MPa}$ and elongation of $4 \pm 1.8 \%$ under as-cast condition. However, the yield strength, UTS and elongation were increased to 154 \pm 7.3 MPa, $180 \pm 10.6 \mathrm{MPa}$ and $10 \pm 2.3 \%$, respectively after heat treatment. For comparison, the tensile properties of original A356 and AA6060 alloys used in the present study were also tested under the same condition separately and shown in Table 2. The A356 alloy showed the yield strength of $80 \pm 6.6 \mathrm{MPa}$, UTS of $160 \pm 15.5 \mathrm{MPa}$ and elongation of 
$4 \pm 1.5 \%$ under as-cast condition. These were increased to $165 \pm 7.1 \mathrm{MPa}$ for the yield strength, $220 \pm 16.2 \mathrm{MPa}$ for the UTS and $4.5 \pm 2.2 \%$ for the elongation under aged condition. Similarly,

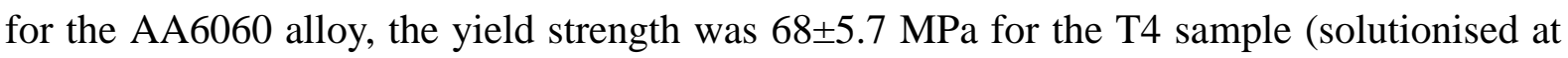
$540^{\circ} \mathrm{C}$ for 4 hours) and 160.4 for the T7 sample. The elongation was $16 \pm 3.6 \%$ for the T4 sample and $10 \pm 3.8 \%$ for the T7 sample. Compared to the original A356 alloy under as-cast condition, the yield strength, UTS and elongation of the overcasting arts were increased by $14 \%, 11 \%$ and $13 \%$, respectively. Similarly, compared to the original AA6060 alloy under aged condition, the yield strength, UTS of the overcasting arts were slightly decreased by $3.7 \%$, and $4.9 \%$, respectively, while the elongation was maintained at the same level. It should be mentioned that there was a decrease of $5 \%$ for the UTS of the overcasting arts compared to the properties of original AA6060 alloys. However, the property loss caused by heat-affected zone (HAZ) in conventional welding is normally 20-30\% (Mahoney et al., 1998). In this regard, the overcasting can significantly improve the joining strength and achieve the similar level of properties to the original wrought alloy.
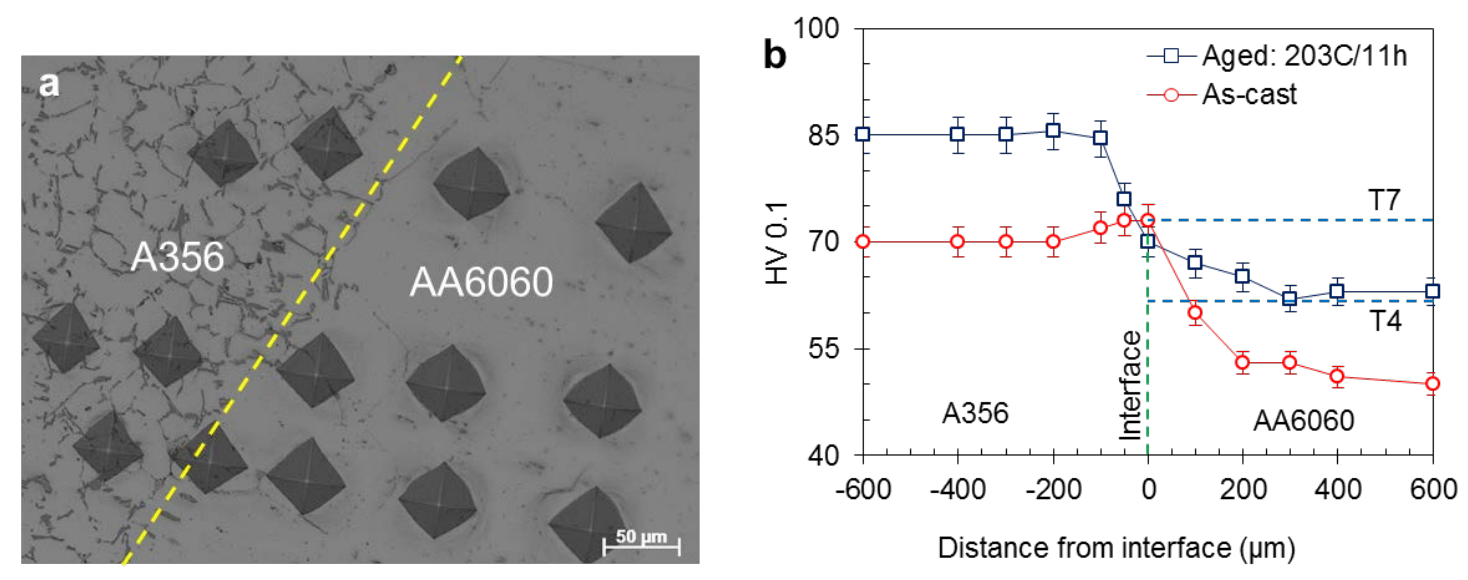

Figure 9 (a) Optical micrograph showing the locations of hardness test near the interface and the microstructure and (b) the hardness across the interface under different conditions.

The HAZ is usually a serious concern in conventional welding process. The work done by Liu et al. (2016) showed that the HAZ was composed of equiaxed grains in various sizes and the hardness in HAZ was lower than that in base metal. Stathers et al. (2014) established the relationships between hardness and tensile properites in the HAZ for the 6060-T651 aluminium alloy via a gas metal arc weld method. In this work, investigation of property 
variation was focused on the AA6060/A356 interface of the overcast structure to verify the characteristics of HAZ during overcasting. Hardness test was performed across the interface. The locations of the dentation and the correspondent hardness results are given in Figs. 9a and 9b, respectively. Under as-cast condition, the hardness was $70 \mathrm{Hv}$ in the cast A356 and $50 \mathrm{Hv}$ in the wrought AA6060 alloy, showing a decrease of 30\%. However, the hardness differences occurred only in the regions about $200 \mu \mathrm{m}$ away from the interface. Beyond the $200 \mu \mathrm{m}$ region on both A356 and AA6060 sides, the hardness showed little variation in each material. This indicated that, after overcasting, the hardness did not show any significant variation in the original alloys. There was no decrease valley of hardness at the interface either. This also meant that there was no obvious heat affected zone in the overcast structure. Similarly, the hardness distribution under aged condition showed the same trend, although the ageing resulted in an increase in hardness by a level of $15 \mathrm{Hv}$ in comparison with that under as-cast condition. After ageing, the hardness of both the A356 and the AA6060 alloys was significantly increased. The value of hardness of AA6060 and A356 was increased by 23\% and $21 \%$, respectively. HAZ was not detected in this case either. Generally, the decrease of hardness could cause the decrease of tensile properties of hybrid materials. In the present study, although the hardness decreased, the tensile properties maintained the same level of the original AA6060 alloy. This indicates that the good interfacial bonding provided by the fine equiaxed grains are critical for the mechanical behaviour.

In Fig. 9, the hardness of the original AA6060 alloy under T7 and T4 conditions is also shown. It is noted that the hardness at the AA6060/A356 interface under both as-cast and aged conditions was very close to the value of the AA6060 alloy under T7 condition. According to the composition analysis crossing the A6060/A356 interface as shown in Fig.6, there was a big difference of the content of Si on interface, A6060 matrix and A356 matrix. The content of Si in precipitate free zone was higher than that of A6060 and lower than that of A356. This means that the diffusion of Si into A6060 matrix was occurred during overcasting. The dissolution of Si into matrix could form solution hardening and resulted in the increasing of hardness of matrix. However, it is interesting to note that the hardness after overcasting was lower than that of the AA6060 alloy under T4 condition. Similarly, the 
hardness in the aged overcasting was lower than that of the AA6060 alloy under the same T7 condition. The results confirmed that the proper bonding could improve the mechanical properties of overcast hybrid materials.

\section{Discussion}

\subsection{Microstructural evolution during overcasting}

The overcasting process is a special casting process with required inserts in the cavity. Because of the temperature of inserts are always lower, the initial thermal undercooling can be from both the inserts and the wall of casting mould. Therefore, the solidification is anticipated to start from the wall of casting mould and/or from the surface of the inserts, which further triggers the constitutional undercooling and initiates the growth of the newly-formed primary $\alpha$-Al phase. Figs. 5\&6 show the formation of the shared grains between the as-cast A356 and the primary $\alpha$-Al grains in the wrought AA6060 alloy.

Morphology of $\alpha$-Al phase at the AA6060/A356 interface was determined by the temperature gradient $(\mathrm{G})$ and the growth velocity $(\mathrm{V})$ of the solid/liquid interface. Fully equiaxed growth occurs when the extended volume fraction $\varphi_{\mathrm{E}}>0.66$ at an undercooling equalling to that of the columnar growth front temperature $\left(\Delta \mathrm{T}_{\mathrm{c}}\right)$. Generally, the temperature gradient is determined by $G>2.9 N_{0}{ }^{1 / 3}\left(1-\Delta \mathrm{TN}_{\mathrm{N}} / \Delta \mathrm{Tc}_{\mathrm{C}}{ }^{3}\right) \Delta \mathrm{T}_{\mathrm{C}}$ (Kurz et al., 2001), where $\varphi_{\mathrm{E}}=4 \pi \mathrm{r}^{3} \mathrm{~N}_{0} / 3, \Delta \mathrm{T}_{\mathrm{C}}=\left(\mathrm{VC}_{0} / \mathrm{A}\right)^{1 / 2}$, $\mathrm{r}$ is the radius of the equiaxed grains, $\Delta \mathrm{T}_{\mathrm{N}}$ is the undercooling at the heterogeneous nucleation temperature. $\mathrm{N}_{0}$ is the total number of heterogeneous substrate particles originally available per unit volume, $\mathrm{C}_{0}$ is the alloy composition and $\mathrm{A}$ is a constant. In the present study, with the pouring temperature of $720^{\circ} \mathrm{C}$, the preheated temperature of AA6060 at $200^{\circ} \mathrm{C}$ would supply reasonable undercooling for $\alpha-\mathrm{Al}$ to nucleate and grow as fine equiaxed grains. On the other hand, Okayasu et al., (2012) reported that the cooling rate at the solidification front can be estimated using $C R=2 \times 10^{4} S D A S^{-2.67}$, where SDAS is the secondary arm spacing. According to the microstructural characteristics in Fig. 5, the SDAS is $23.5 \mu \mathrm{m}$. Therefore, the cooling rate is estimated to be $4.37 \mathrm{~K} / \mathrm{s}$. As such, the cooling rate at a level of $4 \mathrm{~K} / \mathrm{s}$ can lead to the formation of equiaxed $\alpha$ - $\mathrm{Al}$ grains in the overcasting arts. 


\subsection{Microstructural characteristics of overcast hybrid structure}

The successful overcasting gives a clean interface between the AA6060 inserts and A356 overcast alloy. In a desirable case, the oxide films need to be removed from the bonding surface. In the casting structures, the sizes of overflows and their distributions should be carefully designed in order to distribute the oxide films during overcasting. Meanwhile, the control of preheat temperature of solid inserts and the pouring temperatures, and the design of ingate size and locations are also critical to produce a quality overcasting hybrid structure based on cast and wrought aluminium alloys. Because of the characteristics of aluminium alloys, the distortions of solid inserts can be severe if overcasting process is not been properly controlled. Therefore, more attention needs to be paid to the control of the process in order to produce quality overcast arts.

The absence of $\mathrm{Mg}_{2} \mathrm{Si}$ precipitates adjacent the interface is one of the major characteristics in the as-cast microstructure obtained by the overcasting. The temperature of the preheated solid AA6060 inserts is further increased during overcasting and the final temperature is at a relatively high temperature (about $550^{\circ} \mathrm{C}$ as seen in Fig.3). Two diffusion processes are expected to occur. One is the re-solutionisation of solute elements into primary $\alpha$-Al phase during overcasting. The increased temperature in the solid insert near the interface promotes the solutionisation of solute elements. However, as the overcast art is relatively thin and the solidification time is relatively short, the diffusion of solute elements is limited in the solid inserts with a large temperature gradient. This results in the formation of a narrow precipitate-free band in the solid inserts near the interface. The other is the diffusion of solute elements from cast alloys to the $\alpha$-Al phase of the AA6060 insert because of the concentration gradient between these two alloys. By studying the bond strength and mechanical properties of three-layered St/AZ31/St composite, Abedi and Akbarzadeh (2015) revealed that the diffusion layer on interface would enhance the precipitation strengthening and subsequently result in the improvement of interface bonding when it was properly formed.

Traditionally, the columnar grains are the typical characteristics in the weld joining 
microstructure. Ramkumar et al., (2015) revealed that the coarse grain was observed at the HAZ of AISI 430 ferritic stainless steel after TIG welding. The microstructure characteristics of laser-MIG hybrid welded mild steel investigated by Gao et al. (2008) indicated that the microstructure of HAZ was made up of coarse grain region near the weld junction, fine grain region and incomplete recrystallization region near the substrate. The experimental results of Liu et al. (2016) showed that the coarse and larger grain was found in HAZ and the columnar crystals were perpendicular to the fusion boundary. Cao et al. (2014) studied the microstrucutre and properties of $\mathrm{Ti} / \mathrm{Cu}$ welded joints by CMT technology, and found that columnar crystals which grow into the weld metal were distributed in the fusion line zone near $\mathrm{Cu}$ base metal side. The main reason is the specified cooling direction in the welding solidification. In the overcast joining method, the solidification occurs from the solid inserts and the wall of mould. The as-cast microstructure can be fine and equiaxed grains. According to the Hall-Petch theory, the smaller the grain size, the higher the tensile strength. Therefore, the equiaxed grains obtained adjacent to the bonding interface would enhance the bonding strength and benefit the achievement of isotropic properties. Moreover, the bonding is actually formed by forming $\alpha-\mathrm{Al}$ grains at the interface. The $\alpha$-Al grains actually grow from the existing $\alpha$-Al grains on the surface of solid AA6060 insert (Fig.5). This phenomenon has been defined as Grain Growth Heredity (GGH). This kind of joining approach with GGH can bind different materials together in a perfect format. Therefore, the bonded arts can provide the maximum potential with the strongest interface bonding strength.

\subsection{The relationship between microstructure and mechanical properties}

As seen in Fig. 7 and Table 3, the microstructure formed during overcasting and subsequent ageing treatment play a critical role in controlling the strength of the experimental alloy. In the samples processed by overcasting, the microstructure is characterised by the fine and equiaxed primary $\alpha$-Al phase in the cast alloy and the precipitate-free zone in the wrought alloy near the interface, which can provide a higher strength than the relatively coarse primary $\alpha-\mathrm{Al}$ phase in the original cast alloy. Therefore, the fracture occurs in the cast alloy. It needs to emphases that the original strength of as-cast A356 is higher than that of AA6060. In a normal case, the fracture should not occur in A356 during tensile test. However, the 
initial AA6060 is under T4 condition and the preheating at $200^{\circ} \mathrm{C}$ before overcasting has allowed the inserts undergoing an ageing equivalent process. There are precipitates strengthening in the materials and the AA6060 in the overcast hybrid structure is actually under T6 condition. Its strength is more than that of A356 alloy under as-cast condition. Therefore, the fracture occurs in the cast alloy.

After ageing, the cast alloy and the precipitate-free zone are enhanced by precipitates. However, the wrought inserts cannot be further enhanced because the precipitates are already there. In fact, the existing precipitates may have a further growth in the wrought alloy, resulting in the slight reduction of strength in the hybrid structure under aged condition. Therefore, the factures occur in the wrought alloy. However, it is anticipated that the fracture may be different if the solution treatment is applied to the hybrid structure after overcasting, which results from the redistribution of solute contents in the solutionising process.

The relatively higher strain at fracture exhibited by the hybrid materials after ageing is due to the contribution from the wrought alloy. As the increased strength in the cast alloy, the hybrid materials can bear higher stress, during which the wrought alloy can be further extended under tension forces.

After overcasting the hardness of solid AA6060 is at a level of $50 \mathrm{Hv}$, which is even lower than that of AA6060 after extrusion with T7 treatment. This is because that the samples are re-heated to about $550^{\circ} \mathrm{C}$ during overcasting, which is like being re-solutionised, and therefore the materials are softened.

\section{Conclusions}

The interface characterisations of overcasting the Al-Si-Mg (A356) alloy on the wrought Al-Mg-Si (AA6060) alloy have been studied experimentally. The following conclusions can be drawn.

(1) A strong bonding at the AA6060/A356 interface is obtained through overcasting. The oxide film on the surface of AA6060 inserts can be successfully removed by properly 
designed mould structure and good control of overcasting process.

(2) The fine equiaxed primary $\alpha$-Al grains in the A356 can be formed at the bonding interface. The primary $\alpha$-Al grains in the as-cast microstructure of A356 alloy grow directly on the primary $\alpha$-Al grains in the solid inserts of wrought AA6060 aluminium alloys. The EBSD results confirm that these two types of primary $\alpha-\mathrm{Al}$ grains have the same grain orientation and therefore the shared grains are capable of providing improved bonding strength.

(3) The tensile properties of the hybrid materials can be improved through overcasting. When tensile stress is applied, the overcast hybrid arts are fractured in the cast A356 alloy under as-cast condition, but in the solid inserts of the wrought AA6060 alloy under aged condition.

(4) Heat-affected zone is not significant in the overcast structure according to the property variation near the AA6060/A356 interface. The UTS of overcast arts has a slight decrease by $5 \%$ in comparison with those of the original AA6060 alloys under aged condition.

\section{Acknowledgements}

The work was supported by Innovate UK (Project number: 318211), United Kingdom.

\section{References}

Abedi, R., Akbarzadeh, A., 2015. Bond strength and mechanical properties of three-layered St / AZ31 / St composite fabricated by roll bonding. Mater. Des. 88, 880-888.

Arghavani, M.R., Movahedi, M., Kokabi, A.H., 2016. Role of zinc layer in resistance spot welding of aluminium to steel. Mater. Des. 102, 106-114.

Bouayad, A., Gerometta, C., Belkebir, A., Ambari, A., 2003. Kinetic interactions between solid iron and molten aluminium. Mater. Sci. Eng. A 363, 53-61. 
Cao, R., Feng, Z., Chen, J.H., 2014. Microstructures and properties of titanium-copper lap welded joints by cold metal transfer technology. Mater. Des. 53, 192-201.

Dezellus, O., Digonnet, B., Sacerdote-Peronnet, M., Bosselet, F., Rouby, D., Viala, J.C., 2007. Mechanical testing of steel/aluminium-silicon interfaces by pushout. Int. J. Adhes. Adhes. 27, 417-421.

Gao, M., Zeng, X., Yan, J., Hu, Q., 2008. Microstructure characteristics of laser-MIG hybrid welded mild steel. Appl. Surf. Sci. 254, 5715-5721.

Jiang, W., Fan, Z., Li, C., 2015. Improved steel/aluminum bonding in bimetallic castings by a compound casting process. J. Mater. Process. Technol. 226, 25-31.

Kobayashi, S., Yakou, T., 2002. Control of intermetallic compound layers at interface between steel and aluminum by diffusion-treatment. Mater. Sci. Eng. A 338, 44-53.

Koerner, C., Schwankl, M., Himmler, D., 2014. Aluminum-aluminum compound castings by electroless deposited zinc layers. J. Mater. Process. Technol. 214, 1094-1101.

Kurz, W., Bezencom, C., Gaumann, M., 2001. Columnar to equiaxed transition in solidification processing. Sci. Technol. Adv. Mater. 2, 185-191.

Liu, T., Wang, Q., Sui, Y., Wang, Q., Ding, W., 2015. An investigation into aluminumaluminum bimetal fabrication by squeeze casting. Mater. Des. 68, 8-17.

Liu, T., Yan, F., Liu, S., Li, R., Wang, C., Hu, X., 2016. Microstructure and mechanical properties of laser-arc hybrid welding joint of GH909 alloy. Opt. Laser Technol. 80, 56-66.

Liu, Y., Bian, X., Zhang, K., Yang, C., Feng, L., Seop, H., Guo, J., 2014. Interfacial microstructures and properties of aluminum alloys/galvanized low-carbon steel under high-pressure torsion. Mater. Des. 64, 287-293.

Lombardi, A., Sediako, D., Machin, A., Ravindran, C., MacKay, R., 2015. Transient analysis of residual strain during heat treatment of multi-material engine blocks using in-situ neutron 
diffraction. Mater. Lett. 157, 50-52.

Mahoney, M.W., Rhodes, C.G., Flintoff, J.G., Spurling, R.A., Bingel, W.H., 1998. Properties of friction-stir-welded 7075 T651 aluminum. Metall. Mater. Trans. A 29, 1955-1964.

Manasijevic, S., Radiša, R., Brodarac, Z.Z., Dolic, N., Mile Djurdjevic, 2015. Al-Fin bond in aluminum pistion alloy \& austenitic cast iron insert. Int. J. Met. 9, 27-32.

Nerl, C., Wimmer, M., Hoffmann, H., Kaschnitz, E., Langbein, F., Volk, W., 2014. Development of a continuous composite casting process for the production of bilayer aluminium strips. J. Mater. Process. Technol. 214, 1445-1455.

Okayasu, M., Ohkura, Y., Takeuchi, S., Takasu, S., Ohfuji, H., Shiraishi, T., 2012. A study of the mechanical properties of an Al-Si-Cu alloy (ADC12) produced by various casting processes. Mater. Sci. Eng. A 543, 185-192.

Papis, K.J.M., Hallstedt, B., Lo, J.F., Uggowitzer, P.J., 2008. Interface formation in aluminiu-aluminium compound casting. Acta Mater. 56, 3036-3043.

Ramkumar, K.D., Chandrasekhar, A., Singh, A.K., Ahuja, S., Agarwal, A., Arivazhagan, N., Rabel, A.M., 2015. Comparative studies on the weldability, microstructure and tensile properties of autogeneous TIG welded AISI 430 ferritic stainless steel with and without flux. J. Manuf. Process. 20, 54-69.

Rübner, M., Günzl, M., Körner, C., Singer, R.F., 2011. Aluminium - aluminium compound fabrication by high pressure die casting. Mater. Sci. Eng. A 528, 7024-7029.

Schwankl, M., Wedler, J., Körner, C., 2016. Wrought Al - Cast Al compound casting based on zincate treatment for aluminum wrought alloy inserts. J. Mater. Process. Technol. 238, 160168.

Shao, L., Shi, Y., Huang, J.K., Wu, S.J., 2015. Effect of joining parameters on microstructure of dissimilar metal joints between aluminum and galvanized steel. Mater. Des. 66, 453-458. 
Stathers, P.A., Hellier, A.K., Harrison, R.P., Ripley, M.I., Norrish, J., 2014. Hardness-Tensile Property Relationships for HAZ in. Weld. J. 301-s 93, 301-311.

Uthayakumar, M., Prabhakaran, G., Aravindan, S., Sivaprasad, J.V., 2009. Precision machining of an aluminum alloy piston reinforced with a cast iron insert. Int. J. Precis. Eng. Manuf. 10, 7-13.

Viala, J.C., Peronnet, M., Barbeau, F., Bosselet, F., Bouix, J., 2002. Interface chemistry in aluminium alloy castings reinforced with iron base inserts. Compos. Part A Appl. Sci. Manuf. 33, 1417-1420.

Zhang, K., Bian, X., Li, Y., Liu, Y., Yang, C., 2013. New evidence for the formation and growth mechanism of the intermetallic phase formed at the Al/Fe interface. J. Mater. Res. 95, 3279-3287. 
Figure 1 Schematic diagram of (a) overcasting structure with dimensions, (b) mould configuration for gravity overcasting $\left(\mathrm{T}_{\mathrm{e}}\right.$ : the melt temperature at cavity entrance, $\mathrm{T}_{\mathrm{tm}}$ : the temperature of top mould, $\mathrm{T}_{\mathrm{bm}}$ : the temperature of bottom mould, L1, L2, L3, L4, L5 and L6: locations for data acquisition from the calculated solidification and cooling process, and for measuring the temperature distribution).

Figure 2 (a) The tensile sample size and (b) the location of tensile sample machined from the hybrid materials made by overcasting the A356 on the AA6060 solid inserts.

Figure 3 The cooling curves at different locations specified in Fig. 1(a), in which point L1 is the entrance point of the melt into the casting cavity.

Figure 4 Measured cooling curve at the cavity entrance point of the overcasting A356 alloy melt (the location L1 marked in Fig. 1).

Figure 5 The optical micrograph showing the interface between the AA6060 insert and the overcast A356 alloy.

Figure 6 The optical micrograph showing the shared $\alpha$-Al grains at the interface between the A6060 insert and the overcast A356 alloy. And insert table is the composition analysis of selected points crossing the A6060/A356 interface.

Figure 7 (a) SEM image showing the location and microstructural features for EBSD analysis, (b) EBSD image showing the distribution of grain orientation and the color coded map of inverse pole [001] at the interface between the AA6060 insert and the overcast A356 alloy.

Figure 8 Optical images showing the positions of fracture of the overcast AA6060/A356 tensile samples, (a) as-cast, (b) aged at $203^{\circ} \mathrm{C}$ for 11 hours (AA6060 was in T4 condition before being used for overcasting, therefore, the aged sample of the AA6060 alloy was under T7 condition after ageing). 
Figure 9 (a) Optical micrograph showing the locations of hardness test near the interface and the microstructure and (b) the hardness across the interface under different conditions.

Table 1. The chemical compositions of AA6060 and A356 alloys used in the experiments.

Table 2. The mechanical properties of overcast tensile samples and the A356 and AA6060 used in the experiments. 